\title{
Effect of Plastic Deformation on the Activation Energy for Precipitation of S' Phase in $\mathbf{A l}_{2024}$ Alloy
}

J.C. Guía-Tello ${ }^{1}$, C.G. Garay-Reyes ${ }^{1}$, H. M. Medrano-Prieto ${ }^{2}$, M.A. Ruiz-Esparza-Rodriguez ${ }^{1}$, M.C. Maldonado-Orozco $^{3}$, G. Rodriguez-Cabriales ${ }^{1}$ and R. Martínez-Sánchez ${ }^{1}$

${ }^{1}$ Centro de Investigación en Materiales Avanzados (CIMAV), Laboratorio Nacional de Nanotecnología, Chihuahua, Chihuahua, México, ${ }^{2}$ Universidad Autónoma de Ciudad Juárez (UACJ), Ciudad Juárez, Chihuahua, Mexico, ${ }^{3}$ Autonomous University of Chihuahua, Chihuahua, Chihuahua, Mexico

It is well known that the mechanical strength of the 2024 alloys depends on the precipitated phases during the age-hardening treatment, being the $S^{\prime}$ phase one of the most important. However, plastic deformation and thermo-mechanical processing affect the sequence, morphology, and spatial distribution of precipitates, as well as kinetic parameters, for example, the activation energy (Q), which modifies the hardening mechanism [1]. Thus, the activation energy needed for precipitation of $S^{\prime}$ phase was evaluated in this work, which will contribute to establishing its precipitation sequence in the solid-state.

The studied material was commercial 2024 alloy which was subjected to fusion, hot extrusion and solution heat treatment (SHT). The SHT was performed in an electric furnace at $495^{\circ} \mathrm{C}$ for $7 \mathrm{~h}$; subsequently, the samples were quenched in water at $60^{\circ} \mathrm{C}$. Two processing routes were selected to be evaluated: The first one considers only SHT (non-deformation) and the second one considers a plastic deformation of $30 \%$ by cold rolling after SHT. The samples were analyzed through the differential scanning calorimetry (DSC) to evaluate the involved thermal events and determine the effect of processing on the activation on the $S$ phase precipitation. DSC studies were carried out using a Modulated-DSC from TA Instruments model 2920. The used temperature range was $25-350^{\circ} \mathrm{C}$ following heating rates of $5,10,15$ and $20^{\circ} \mathrm{C} / \mathrm{min}$ for all samples. Several disk shape $(2 \times 1 \mathrm{~mm}$, diameter and thickness) samples were prepared. In order to assure the reproducibility of the measurements, each sample was repeated 3 times, and the average was reported. The kinetics of the precipitation process was obtained following the Kissinger and Ozawa models [2]. Deformed and non-deformed samples were prepared by Focused Ion Beam (FIB) operated at $5-30 \mathrm{kV}$ (step $5 \mathrm{kV}$ ). The samples were analyzed in STEM mode using a transmission electron microscope JEM $2200 \mathrm{FS}+\mathrm{CS}$ operated at $200 \mathrm{kV}$ and equipped with a spherical aberration corrector.

Table I shows an overview of the activation energy calculated for the precipitation of S' phase through a Kissinger analysis; also, a comparison with those values obtained following the Ozawa model and enthalpy formation were included. As can be seen, in all cases, the activation energy calculated by the Kissinger equation is $\sim 5 \%$ lower compared to the measurements obtained by the Ozawa method. However, following both models, there is a clear trend in which the deformed samples required lower energy for precipitation. This indicates that exists an important effect on the solid-state precipitation phenomenon. Such effect could be understood because the deformation introduces a high density of dislocations in the structure which favors the precipitation mechanism due to the generation of high diffusion paths and nucleation sites [3], but as can be seen in Figure 1, the deformation grade also influence in the morphology and size of the $S^{\prime}$ precipitates, which could have a significant effect on the strengthening of the alloy. 


\begin{tabular}{ccccc}
\hline Sample & Kissinger & Ozawa & $\Delta \mathbf{H}\left(\mathbf{H}_{\mathbf{R}=\mathbf{2 0}}{ }^{\circ} \mathbf{C} \mathbf{m i n}\right)$ & $\Delta \mathbf{H}_{\text {Average }}$ \\
\hline ND & $\mathbf{1 4 2 . 3} \pm 5.8$ & $\mathbf{1 5 1 . 2} \pm 5.8$ & 17.31 & 17.7 \\
$\mathbf{3 0 \% D}$ & $\mathbf{1 2 4 . 6} \pm 3.4$ & $\mathbf{1 3 3 . 3} \pm 3.4$ & 14.13 & 14.1 \\
\hline
\end{tabular}

Figure 1. Table I. Summary chart of the activation energy (Q, in $\mathrm{kJ} / \mathrm{mol})$ and enthalpy of formation (DH, in $\mathrm{J} / \mathrm{g}$ ) for the precipitation of $\mathrm{S}^{\prime}$ phase.
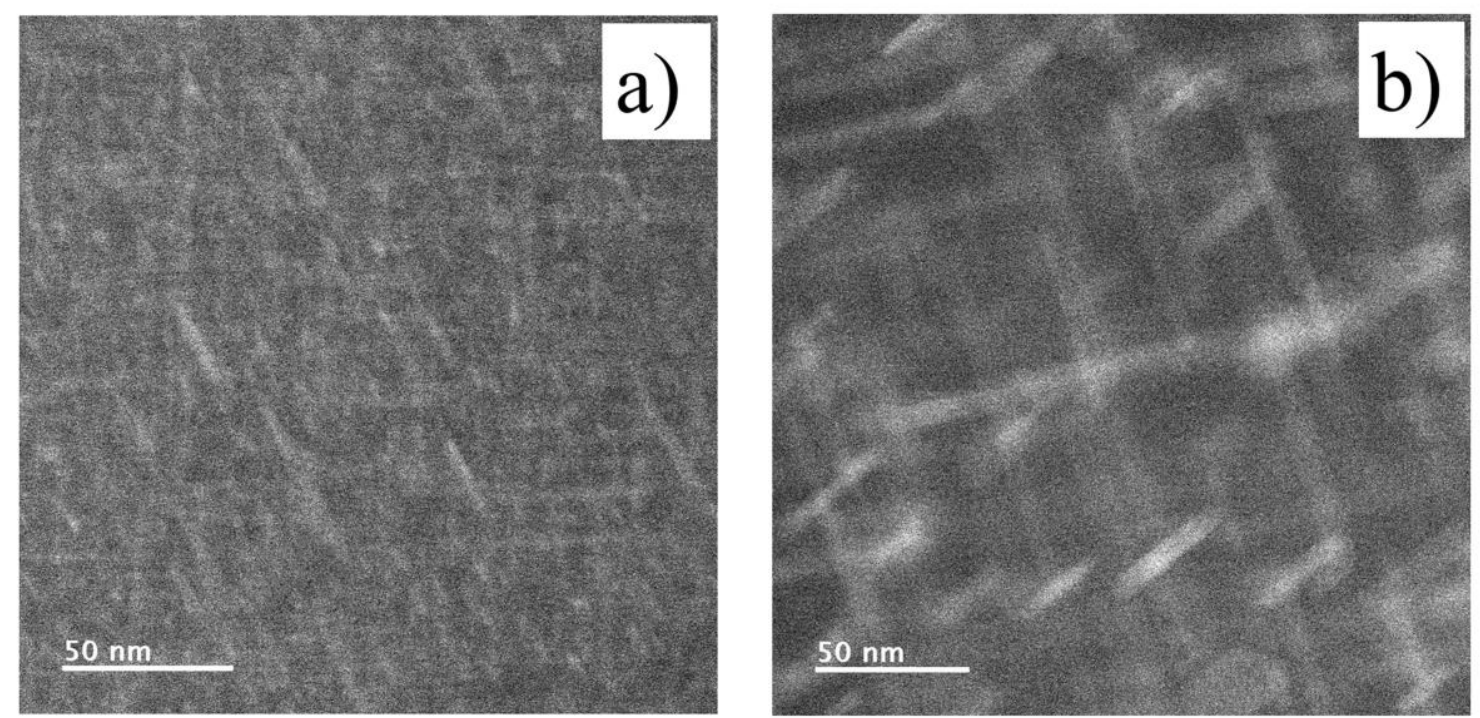

Figure 2. Figure 1. STEM micrographs corresponding to Al2024 alloy samples: a) non-deformed; b) deformed $30 \%$ by cold rolled.

\section{References}

[1] H.Z. Li, R.M. Liu, X.P. Liang, M. Deng, H.J. Lia, L. Huang, Trans. Nonferrous Met. Soc. China 26 (2016) 1482-1490.

[2] M. Fatmi, B. Ghebouli, MA Ghebouli, T. Chihi, MA Hafiz, Physica B 406 (2011) 2277-2280.

[3] C. Badini, F. Marino, E. Verné, Mater Sci Eng A 191 (1995) 185-191. 